\title{
Antibiotic and shared decision-making preferences among adolescents in Malaysia
}

\author{
This article was published in the following Dove Press journal: \\ Patient Preference and Adherence \\ 13 May 2015 \\ Number of times this article has been viewed
}

\section{Irma Wati Ngadimon \\ Farida Islahudin \\ Ernieda Hatah \\ Noraida Mohamed Shah \\ Mohd Makmor-Bakry}

Faculty of Pharmacy, Universiti Kebangsaan Malaysia, Kuala Lumpur, Malaysia
Correspondence: Farida Islahudin Faculty of Pharmacy, Universiti Kebangsaan Malaysia, Jalan Raja Muda Abdul Aziz, 50300 Kuala Lumpur, Malaysia

Tel +60392897689

Email faridaislahudin@yahoo.com
Background: The purpose of this study was to establish baseline information on the current level of knowledge about, attitude toward, and experience with antibiotic usage, and preferences for shared decision making among adolescents in Malaysia.

Methods: A cross-sectional survey, involving 1,105 respondents who were aged between 13 and 17 years and who lived in Malaysia, was conducted using a validated questionnaire. The survey assessed knowledge, attitude, and experience with regard to antibiotic usage, and adolescents' preferences for the style of shared decision-making process.

Results: The majority ( $\mathrm{n}=786$ [71.13\%]) of the respondents had a low level of knowledge, 296 (26.79\%) had a moderate level of knowledge, and 23 (2.08\%) had a high level of knowledge. Further, they demonstrated a slightly negative attitude mean score of $3.30 \pm 0.05$ (range: $0-8$ points) but a positive experience mean score of $2.90 \pm 0.029$ (range: $0-4$ points). There was a positive correlation between knowledge and attitude scores, with a higher knowledge level associated with a more positive attitude toward antibiotic usage $(r=0.257, P<0.001)$. Higher knowledge scores were associated with a more negative experience with antibiotic usage ( $r=-0.83, P=0.006)$. When assessing preference in shared decision making, more adolescents preferred an active role $(n=408$ [37\%]) compared with collaborative $(n=360$ [32.6\%]) or passive $(\mathrm{n}=337[30.5 \%])(P=0.028)$ roles.

Conclusion: Current health care settings should involve adolescents in the decision-making process. Education packages can be introduced to improve adolescents' knowledge of and practice of taking antibiotics, as well as to encourage their participation in decision making, in an attempt to reduce misuse of antibiotics.

Keywords: antibiotic usage, knowledge, attitude, experience

\section{Introduction}

In the health care context, shared decision making is a multifaceted process that often involves both the physician and patient. ${ }^{1}$ The model of health care decision making has been widely accepted during medication prescribing and is used in order to ensure adherence is optimized. During the decision-making process, a number of important factors are considered in order to ensure appropriate medication is prescribed in each individual case. ${ }^{2}$ Further, it is clearly noted in this model that the decision-making process should involve adult patients and their clinicians. ${ }^{3,4}$ Although adolescents are also prescribed medications, there is lack of research into the inclusion of adolescents in this decision-making process. However, within the past decade, adolescents have been increasingly encouraged toward a more collaborative involvement in their health care, as this has been shown to improve treatment outcomes. ${ }^{5}$ By involving adolescents in decision making, adherence to medication and treatment may be improved. ${ }^{4}$

Interestingly, previous work has shown that risk factors involved in nonadherence to antibiotic usage have been as widely studied in adolescents as they have in adults. 
Apart from demographic factors, such as ethnicity, ${ }^{6}$ nonadherence in adolescents between the ages of 12 to 20 years has been shown to occur due to an unwillingness to take antibiotics, an increased frequency of drug taking being required, and a lack of commitment from parents in enforcing antibiotic usage. ${ }^{6,7}$ A lack of understanding of the correct use of antibiotics is also a driving factor in poor adherence among adolescents. ${ }^{7}$ Interestingly, nonadherence to antibiotics has been shown to be associated with reduced involvement in decision making in adults. ${ }^{8}$ The involvement of adults in decision making through patient education improves knowledge of disease states and their effects. ${ }^{9}$ Therefore, it is possible that improving knowledge will also be associated with an increased level of decision making in adolescents.

One of the main concerns of antibiotic nonadherence in adolescents relates to incorrect usage. The prescription of antibiotics to adolescents is a common occurrence; however, the decision of whether or not the adolescent actually takes the antibiotics is usually left to the adults, ${ }^{10}$ and this can lead to a lack of adherence. Mismanagement of antibiotics can lead to an array of problems later in life, one of which is antibiotic resistance, which is a major issue worldwide. ${ }^{11}$ The frequency of bacterial resistance has increased markedly within the past few years, with resistance to first-generation antibiotics reported to be as high as $82 \% .{ }^{11}$ Thus, proper use of antibiotics and good adherence to taking the drug should be ensured, due to the ease of resistance. ${ }^{12}$

Studies have shown that the understanding of correct antibiotic usage among respondents in Asia can be improved markedly; ${ }^{13,14}$ however, there is a lack of data on the basic understanding of antibiotic usage in adolescents, along with their perception of the benefits of, attitudes toward, and involvement with the drug, in the context of local populations in Malaysia. Indeed, this information would be especially useful in a country with many ethnicities, where both decision making and adherence may differ between ethnicities. ${ }^{6}$ Previous work has shown that with better knowledge, patients become more likely to collaborate in decision making, which greatly improves adherence to treatment. ${ }^{9}$ Knowledge and attitude can be directly improved through educational packages for adolescents. This is of great benefit as improving adherence is a step toward reducing antibiotic resistance in the long term. Therefore, examining the nature of adolescents' knowledge, attitude, past experience, and involvement through shared decision making could improve our understanding of poor antibiotic adherence among this population. Thus, it is hypothesized that adolescents with better knowledge, attitudes, and experience will be more willing to collaborate in decision making with their caregivers and clinicians. This was a baseline study to assess adolescents' knowledge of, attitude toward, and experience with antibiotic usage, and their preference about engaging in the shared decision-making process.

\section{Methods \\ Study design}

This study performed a cross-sectional survey with a stratified random sample of secondary school students. A sample size of 383 was required from a population of 2,344,891 secondary school students in Malaysia, based on the Krejcie and Morgan formula; ${ }^{15}$ however, 1,105 students from 14 schools, across 14 states, were recruited to increase the power of the study and allow for subgroup analysis. These students were aged between 13 and 17 years, and were able to read the Malay and/or English language. Parents or caregivers of the students included in the study were also invited to participate. Respondents were included in the study sample after they gave both oral and written informed consent. Those who did not complete the questionnaire were excluded from the study. Ethical approval was obtained from the Malaysian National Research and Ethics Committee (UKM 1.5.3.5/244/ NF-045-14).

\section{Measures}

The respondents answered self-administered questionnaires to assess demographic variables, such as sex, age, ethnicity, knowledge of antibiotic use, ${ }^{14}$ attitude toward antibiotics, ${ }^{14}$ and previous experience with antibiotics, ${ }^{13}$ and completed the Control Preferences Scale (CPS). ${ }^{16,17}$ Parents were asked to answer questionnaires to assess demographics and to complete the CPS. Questionnaires were personally distributed by the researchers and collected on the same day. Face and content validation of the questionnaire was undertaken by a panel of five hospital pharmacists with experience in infectious disease and pediatrics. Feedback was gathered to improve the questionnaire presentation, clarity, and congruency in meaning. Modifications were made, and a pilot test was performed among 40 respondents. The Cronbach's alphas for knowledge of antibiotic use, attitude toward antibiotics, and experience with antibiotics were $0.72,0.87$, and 0.82 , respectively.

\section{Knowledge of antibiotics}

In Malaysia, antibiotics can only be obtained from a pharmacy or a medical clinic, with a prescription issued by a medical doctor. The respondent's knowledge about antibiotic usage was evaluated using a validated questionnaire adapted and modified from previous work. ${ }^{14}$ This consisted of 
Table I Adolescents' knowledge of antibiotic use

\begin{tabular}{|c|c|c|c|c|c|}
\hline No & Knowledge statements & Correct, n (\%) & Incorrect, n (\%) & Unsure, n (\%) & $P$-value ${ }^{a}$ \\
\hline I & Antibiotics are medicines that can kill bacteria & $871(78.8)$ & $73(6.6)$ & $161(14.6)$ & $<0.001$ \\
\hline 2 & Antibiotics can be used to treat viral infections & $205(18.6)$ & $554(50.1)$ & $346(31.3)$ & $<0.001$ \\
\hline 3 & Antibiotics work on most colds and coughs & $221(20.0)$ & $568(51.4)$ & $316(28.6)$ & $<0.001$ \\
\hline 4 & $\begin{array}{l}\text { Antibiotics can kill bacteria that normally live on the } \\
\text { skin and gut (digestive tract) }\end{array}$ & $430(38.9)$ & $261(23.6)$ & $4 \mid 4(37.5)$ & $<0.001$ \\
\hline 5 & $\begin{array}{l}\text { Bacteria that normally live on the skin and in the gut } \\
\text { are good for your health }\end{array}$ & $203(18.4)$ & $454(4 I . I)$ & $448(40.5)$ & $<0.001$ \\
\hline 6 & $\begin{array}{l}\text { Antibiotics are the same as medications used to relieve } \\
\text { pain and fever, such as paracetamol (eg, Panadol) }\end{array}$ & $338(30.6)$ & $537(48.6)$ & $230(20.8)$ & $<0.001$ \\
\hline 7 & Penicillin is an antibiotic & $325(29.4)$ & $102(9.2)$ & $678(6 \mathrm{I} .4)$ & $<0.001$ \\
\hline 8 & Antibiotics may cause allergic reaction & $516(46.7)$ & $163(14.8)$ & $426(38.6)$ & $<0.001$ \\
\hline 9 & Antibiotics do not cause side effects & $337(30.5)$ & $392(35.5)$ & $376(34.0)$ & 0.114 \\
\hline 10 & $\begin{array}{l}\text { Overuse of antibiotics can cause the antibiotics to } \\
\text { lose effectiveness in the long term }\end{array}$ & $607(54.9)$ & $168(15.2)$ & $330(29.9)$ & $<0.001$ \\
\hline II & $\begin{array}{l}\text { It is okay to stop taking an antibiotic when symptoms } \\
\text { are improving }\end{array}$ & $323(29.2)$ & $594(53.8)$ & $188(17.0)$ & $<0.001$ \\
\hline 12 & $\begin{array}{l}\text { Taking less of the antibiotics than prescribed is } \\
\text { healthier than taking the full prescribed course }\end{array}$ & $494(44.7)$ & $234(2 \mid .2)$ & $377(34.1)$ & $<0.001$ \\
\hline
\end{tabular}

Notes: $\mathrm{N}=1,105$. ${ }^{\mathrm{a}} \mathrm{Chi}$-squared test significance set at $\mathrm{P}<0.05$.

12 knowledge statements that required the respondents to respond "Yes", "No", or "Not sure". Areas assessed pertained to the role of antibiotics (statements 1 to 4), knowledge about bacteria (statement 5), identification of antibiotics (statements 6 and 7), the proper response to adverse effects of antibiotics (statements 8 to 10), and administration of antibiotics (statements 11 and 12) (Table 1). An arbitrary scoring system was used to assess the level of knowledge, based on the answers provided..$^{14}$ Each correct answer scored 1 mark, while 0 was given for each wrong or unsure response, so the maximum obtainable correct score was 12 . A score of 0 was used for wrong or unsure answers, as both demonstrated the respondents did not have appropriate knowledge of the statements tested. The scores were then summed, and the total knowledge score was categorized into three levels, indicating a low (0-4), moderate (5-8), or high (9-12) level of knowledge. ${ }^{14}$

\section{Attitude toward antibiotics}

A further eight statements were used to address students' attitudes toward antibiotic usage, as previously described (Table 2). ${ }^{14}$ The questions addressed usage of antibiotics during colds, patients' expectations of their doctor, completion of treatment course, antibiotic sharing, maintenance of

Table 2 Adolescents' attitude toward antibiotic use

\begin{tabular}{|c|c|c|c|c|c|}
\hline No & Attitude statements ${ }^{a}$ & Agree, n (\%) & Not sure, n (\%) & Disagree, n (\%) & $P$-value \\
\hline I & $\begin{array}{l}\text { When I get a cold, I will take antibiotics } \\
\text { to help me get better more quickly }\end{array}$ & $557(50.4)$ & $263(23.8)$ & $285(25.8)$ & $<0.001$ \\
\hline 2 & $\begin{array}{l}\text { I expect antibiotics to be prescribed by my } \\
\text { doctor if I suffer from common cold symptoms }\end{array}$ & $632(57.2)$ & $244(22.1)$ & $229(20.7)$ & $<0.001$ \\
\hline 3 & $\begin{array}{l}\text { I should stop taking an antibiotic when I start } \\
\text { feeling better }\end{array}$ & $724(65.5)$ & $205(18.6)$ & $176(\mid 5.9)$ & $<0.001$ \\
\hline 4 & $\begin{array}{l}\text { If my family member is sick, I should give my } \\
\text { antibiotics to them }\end{array}$ & $347(3 \mid .4)$ & $381(34.5)$ & $377(34.1)$ & 0.392 \\
\hline 5 & $\begin{array}{l}\text { I normally keep a stock of antibiotics at home } \\
\text { in case of emergency }\end{array}$ & $503(45.5)$ & $324(29.3)$ & $278(25.2)$ & $<0.001$ \\
\hline 6 & $\begin{array}{l}\text { I will use leftover antibiotics for a respiratory } \\
\text { illness (runny nose/sore throat/flu) }\end{array}$ & $246(22.3)$ & $384(34.8)$ & $475(43.0)$ & $<0.001$ \\
\hline 7 & $\begin{array}{l}\text { I will take antibiotics according to the } \\
\text { instruction on the label }\end{array}$ & $956(86.5)$ & $107(9.7)$ & $42(3.8)$ & $<0.001$ \\
\hline 8 & $\begin{array}{l}\text { I will look at the expiry date of antibiotics } \\
\text { before taking them }\end{array}$ & $948(85.8)$ & $97(8.8)$ & $60(5.4)$ & $<0.001$ \\
\hline
\end{tabular}

Notes: $\mathrm{N}=\mathrm{I}$, 105. aPositive attitudes were rated as follows: "Disagree", for statements I-6; and "Agree", for statements 7 and 8 . ' $\mathrm{Chi}$-squared test significance set at $P<0.05$. 
antibiotic stocks for emergency use, use of leftover antibiotics, compliance with following the instructions on the label, and the reading of expiry date before taking the antibiotics. A three-point Likert scale, with response options of "Agree", "Not sure", and "Disagree", was used. A higher level of agreement indicated more appropriate antibiotic usage, while greater disagreement indicated the opposite. The option of "Disagree" for statements 1 to 6 and of "Agree" for statements 7 and 8 indicated a positive attitude. A positive attitude was given a score of 1 , whereas a negative attitude was given a score of 0 . Respondents who answered "Not sure" were also given a score of 0 , as this demonstrated that they did not have the correct attitude toward antibiotic usage. Total scores ranged from 0 to 8 , with a higher total score demonstrating a more positive attitude toward antibiotics. ${ }^{14}$

\section{Experience with antibiotics}

Participants' previous experience with antibiotics was evaluated with a questionnaire used in previous work. ${ }^{13}$ Respondents indicated "Yes" if they had faced an experience similar to the statements given, or "No" if they had not. The statements include the following: 1) "I felt better after taking medicine"; 2) "I experienced undesirable effects after taking certain types of medicine"; 3) "I had to take medicine that tasted terrible"; and 4) "I remember not getting well even after I took medicine". "Yes" indicated a positive experience for statement 1 but a negative experience for statements 2-4. A score of 1 indicated a positive experience, whereas a negative experience was given a score of $0 .{ }^{13}$ Total scores ranged from 0 to 4 , with a higher score indicating a more positive experience.

\section{Preference for shared decision making}

The Control Preferences Scale (CPS) was used to evaluate respondents' preference for participation in the shared decision-making process. ${ }^{16,17}$ This scale measures the respondent's desired preference for level of control in treatment decision making, ${ }^{18}$ using five statements to indicate different response categories that best describe the extent to which the respondents want to be involved in treatment decision making. On the basis of their responses, respondents were categorized as preferring an active ("I prefer to make the final decision" or "I prefer to make the final decision after seriously considering my parents' opinion"), collaborative ("I prefer that my parents and I share responsibility for the decision"), or passive ("I prefer that my parents make the decision after he/she seriously considers my opinion" or "I prefer my parents to make the decision") role. Parents were asked to answer two sets of scenarios using the CPS, comprising their willingness to allow their child to be involved in decision making, and their preference for working with doctors and their child in decision making.

\section{Data analyses}

All analyses were performed using SPSS version 22.0 (IBM Corp, Armonk, NY, USA). Demographic characteristics and knowledge of, attitude toward, and experience level with antibiotics were summarized using descriptive statistics. Pearson product-moment correlations and chi-squared tests were used to evaluate the associations among knowledge of, attitude toward, and experience with antibiotics, and preference to engage in shared decision making. In all statistical analysis, $P<0.05$ was considered to be statistically significant.

\section{Results}

\section{Demographic characteristics}

Of 1,400 questionnaires distributed to school students, 1,300 $(93 \%)$ were returned and 1,105 (85\%) of those were considered valid and suitable for analysis. Of the respondents, 599 were female (54.2\%) and 506 were male (45.8\%). Further, $644(58.3 \%)$ were in the lower forms (aged 13-15 years) and 461 in the upper forms (aged 16-17 years). There was a significantly $(P<0.001)$ higher number of Malay $(\mathrm{n}=514$ [46.5\%]) participants compared with those of Chinese $(n=234$ [21.2\%]), Indian ( $n=194$ [17.6\%]) and other ethnicities $(n=163[14.8 \%])$. A significantly smaller percentage $(n=243$ [22\%]) had a family member that worked in health care than those who did not $(\mathrm{n}=862[78 \%])(P<0.001)$. Of the adolescents, $77(7 \%)$ had a long term disease, while 1,028 (93\%) did not $(P<0.001)$. The majority of the respondents $(n=625$ [56.6\%]) visited government hospitals/clinics for health care, while the rest preferred private clinics/hospitals ( $\mathrm{n}=339$ $[30.7 \%])$ or a pharmacy $(\mathrm{n}=141[12.8 \%])(P<0.001)$.

Of 1,400 questionnaires that were distributed to the parents of the adolescents included in the study, 500 were returned (36\% response rate). Of these, 118 were incomplete, so the final sample included 382 parents. There was an equal number of male and female respondents $(n=191$ [50\%], respectively), with the majority aged between 41 and 50 years $(n=202[52.9 \%])$. A significant number $(P<0.001)$ were of Malay ethnicity $(n=300[78.5 \%])$, followed by an equal number of Indian and other ethnicities $(n=31$ [8.1\%], respectively), and then Chinese ( $\mathrm{n}=20$ [5.2\%]). The education level of the parents or caregivers varied, with 39 (10.2\%) having obtained a primary school education, 231 (60.5\%) a secondary school education, and $112(29.3 \%)$ a tertiary level 
education. A significantly smaller $(P<0.001)$ percentage of respondents $(n=103[27 \%])$ had a family member that worked in health care than those who did not $(n=279$ [73\%]), while $53(13.9 \%)$ had a long term illness and 329 (86.1\%) did not $(P<0.001)$.

\section{Knowledge of, attitude toward, and experience with antibiotic use}

The majority of the respondents $(n=786$ [71.13\%]) had a low level of knowledge, with a mean $( \pm$ standard deviation [SD]) score of $3.56 \pm 0.064$ (range $=0$ to 12 , median $=3.0$ ). A moderate level of knowledge was observed in 296 $(26.79 \%)$ of the respondents, and only $23(2.08 \%)$ had a high level of antibiotic knowledge. Overall, statistically significant differences in knowledge level were noted among age group $(P<0.001)$, sex $(P=0.008)$, ethnicity $(P<0.001)$, and health care location $(P<0.001)$. A low level of knowledge was found in the younger age group $(74.4 \%)$, in females (75\%), and in participants of Indian ethnicity (78.4\%). Low knowledge was also more often observed in respondents that used government facilities for health care $(\mathrm{n}=475[76 \%])$ $(P<0.001)$. The percentages of correct and incorrect answers to the 12 statements are shown in Table 1.

The attitude score ranged from 0 to 8 points, with respondents demonstrating a mean $( \pm$ SD) score of $3.30 \pm 0.05$ (median $=3.0)$. A higher attitude score demonstrated a more positive attitude. Consistent with the above results with regard to knowledge about antibiotics, younger age $(P=0.038)$, Indian ethnicity $(P=0.015)$, and using government settings for health care $(P=0.048)$ were significantly associated with negative attitudes toward antibiotic usage. The percentages of positive and negative responses to the eight statements are summarized in Table 2.

Overall, the respondents showed a favorable positive experience with antibiotics, with a mean ( \pm SD) score of 2.90 \pm 0.029 . A statistically significant difference was observed for ethnicity, with a more positive experience with antibiotics being observed in Malay participants (2.99 \pm 0.90$)$ $(P=0.016)$ compared with those of other ethnicities. Table 3 shows the percentage of positive and negative responses to the four statements.

Further analysis of the correlations among knowledge about, attitude toward, and experience with antibiotics was performed, and the results showed that a higher knowledge score was associated with a more positive attitude toward antibiotics $(r=0.257)(P<0.001)$. It was also observed that a higher knowledge score was correlated with a more negative experience with antibiotics ( $r=-0.83, P=0.006)$. There was no significant correlation between experience and attitude scores.

\section{Shared decision making}

In terms of shared decision-making style, a significantly ( $P=0.028)$ higher number of adolescents preferred the active $(n=408[37 \%])$ or collaborative $(n=360$ [32.6\%]) versus passive $(n=337[30.5 \%])$ style, as shown in Table 4 . There was a statistically significant association between CPS score and sex $(P=0.027)$ as well as between CPS score and ethnicity $(P<0.001)$. More male respondents $(n=206$ [40.7\%]) and those of Malay ethnicity ( $n=206$ [42.6\%]) were willing to engage in active decision making.

The parents were also given a set of CPS questions to measure the degree to which they preferred their children to be engaged in shared decision making and how they, as caregivers, preferred to engage with clinicians regarding their child's illness. Results showed that 84 (22\%) parents/ caregivers preferred that their children be actively involved in shared decision making, 117 (30.6\%) preferred a more collaborative role, and 181 (47.4\%) preferred children's passive involvement. On the other hand, a significantly high number of parents $(n=154[40.3 \%])$ preferred a more collaborative role in decision making when it involved both their child and the clinician, with a further $111(29.1 \%)$ preferring an active role and $117(30.6 \%)$ a more passive role. Parents/caregivers with a higher (tertiary) level of education were more willing to allow their child to actively engage in decision making $(\mathrm{n}=67[59.8 \%])(P=0.006)$. No other significant associations were found among CPS scores and the other demographic

Table 3 Adolescents' experience with antibiotics

\begin{tabular}{lllll}
\hline No & Experience statements & Yes, n (\%) & No, n (\%) & P-value \\
\hline I & I felt better after taking medicine & I63(I4.8) & $942(85.2)$ & $<0.00$ I \\
2 & I have experienced undesirable effects after taking certain & I69(I5.3) & $936(84.7)$ & $<0.00$ I \\
& types of medicine & $539(48.8)$ & $566(51.2)$ & 0.417 \\
3 & I had to take medicine that tasted terrible & $330(29.9)$ & $775(70.1)$ & $<0.00$ I \\
\hline
\end{tabular}

Notes: $\mathrm{N}=\mathrm{I}, 105$. ${ }^{\mathrm{a}} \mathrm{Chi}$-squared test significance set at $P<0.05$. 
Table 4 Adolescents' scores on the Control Preferences Scale

\begin{tabular}{|c|c|c|c|c|}
\hline No & CPS statement & Category & n (\%) & $P$-value ${ }^{a}$ \\
\hline I & I prefer to make the final treatment decision & Active & $172(15.6)$ & $<0.001$ \\
\hline 2 & $\begin{array}{l}\text { I prefer to make the final treatment decision after } \\
\text { seriously considering my parents' opinion }\end{array}$ & Active & $236(21.4)$ & \\
\hline 3 & $\begin{array}{l}\text { I prefer that my parents and I share responsibility } \\
\text { for deciding which treatment is the best }\end{array}$ & Collaborative & $360(32.6)$ & \\
\hline 4 & $\begin{array}{l}\text { I prefer that my parents make the final treatment } \\
\text { decision, but seriously consider my opinion }\end{array}$ & Passive & $176(15.9)$ & \\
\hline 5 & I prefer to leave all the treatment decisions to my parents & Passive & $161(14.6)$ & \\
\hline
\end{tabular}

Notes: $\mathrm{N}=1,105$. a Chi-squared test significance set at $\mathrm{P}<0.05$.

Abbreviation: CPS, Control Preferences Scale.

characteristics; however, it was observed that parents who were willing to engage in the collaborative style of shared decision making with their child and doctor were more likely to also allow their child to collaborate in decision making $(\mathrm{n}=64[54.7 \%])\left(\chi^{2}=54.02, P<0.001\right)$ (Table 5). Analysis of parent-child dyads demonstrated no association between parents and adolescents in terms of preference for engaging in decision making.

\section{Discussion}

The main study aim of assessing knowledge of, attitude toward, and experience with antibiotics, and their preference for engaging in shared decision making with regard to antibiotic usage, among adolescents in a local population in Malaysia, was successfully achieved. Acquiring appropriate knowledge of correct antibiotic usage has been shown to reduce the risk of nonadherence to the antibiotics, ${ }^{19,20}$ and this has become an important issue in view of the worldwide rise in antibiotic resistance. Furthermore, with better knowledge of disease, patients' preference for being involved in decision making generally improves, which also leads to better adherence. ${ }^{21}$ It is for this reason that we aimed to identify both adolescents' and parents' basic knowledge about, attitude toward, and experience with antibiotics, and preference for engaging in shared decision making. Nonetheless, although work has shown that preadolescent children aged 7 years and over are able to participate in medical decisions, they do not have full decision-making ability. ${ }^{22}$ The capacity for abstract thought has been shown to develop in the formal operational stages of cognitive development, beginning from around 12 years of age. ${ }^{23}$ At this time, young people are able to consider both short- and long-term consequence ${ }^{23,24}$ and should be assessed on an individual basis with regards to their decision-making capacity. ${ }^{23-25}$ As such, respondents included in the present study were adolescents attending secondary school who were above the age of 12 years. The unique multiethnic distribution of the participants in our study is reflective of the current Malaysian population, ${ }^{26}$ although generalization of our results should be done with caution. As school students make up approximately $34 \%$ of the population in Malaysia, ${ }^{26}$ identification of students' baseline knowledge of antibiotic usage and their preference for being involved in the shared decision-making process will allow for better long-term management of antibiotic resistance.

Various studies have been performed to assess young people's knowledge about and attitude toward antibiotics, in the hope of overcoming antibiotic resistance. . $3,27,30^{-}$ Knowledge about and attitude toward antibiotics among the general public in Malaysia have been shown to be generally moderate, ${ }^{14,28-30}$ however, a significant majority of the adolescents in the current study population were found to have a low level of knowledge of antibiotics. Most alarming was the very small percentage $(2 \%)$ of respondents in the local Malaysian population with a high level of antibiotic

Table 5 Association between parents' willingness to engage in decision making with adolescents and doctor, and their willingness to involve their child in the decision-making process

\begin{tabular}{|c|c|c|c|c|}
\hline \multirow{2}{*}{$\begin{array}{l}\text { Parents' willingness to } \\
\text { involve their child in the } \\
\text { decision-making process }\end{array}$} & \multicolumn{3}{|c|}{$\begin{array}{l}\text { Parents' willingness to engage in decision making with child } \\
\text { and doctor, } n(\%)\end{array}$} & \multirow[t]{2}{*}{$P$-value } \\
\hline & Active & Collaborative & Passive & \\
\hline Active & 77 (42.5\%) & 64 (35.4\%) & $40(22.1 \%)$ & $<0.001$ \\
\hline Collaborative & $23(19.7 \%)$ & 64 (54.7\%) & $30(25.6 \%)$ & \\
\hline Passive & II (13.1\%) & 26 (31.0\%) & 47 (56.0\%) & \\
\hline
\end{tabular}

Notes: $\mathrm{N}=382 .{ }^{2} \mathrm{C}$ i-squared test significance set at $\mathrm{P}<0.05$. 
knowledge. Room for improvement in this area is, thus, evident in the current study. This is especially true as similar work in Asia has shown that a higher number of adolescents had better knowledge and attitude toward antibiotics ${ }^{13,31}$ than in the current study population. One of the main concerns relates to the inability of the adolescents to describe the correct usage of antibiotics, which was similarly found in previous work. ${ }^{5,31}$ Nonetheless, it was interesting to see that the level of knowledge about and attitude toward antibiotics improved with age. Racial distribution, however, revealed that people of Indian ethnicity were less likely to have a high level of knowledge about and attitude toward antibiotics when compared with other ethnicities. The reasons behind this finding require further investigation.

The study results provide valuable data for making plans focused on antibiotic knowledge improvement. In line with this, individuals that attend private clinics or hospitals were found to have better knowledge about and attitude toward antibiotics than were those attending government facilities and retail pharmacies. This could be because private health care facilities in Malaysia have fewer patients and, thus, are able to spend more time explaining to patients the need for and proper usage of the drugs. Indeed, previous research has shown that patient education by health care providers is useful in achieving better knowledge of correct antibiotic usage. ${ }^{32}$ Interestingly, the positive correlation between knowledge and attitude suggests that if knowledge is improved through education, a more positive attitude will also be observed. However, it is important to note that apart from knowledge, experience with antibiotics has also been shown to shape a person's attitude. ${ }^{32}$

Previous experience with antibiotics is an important driving factor in determining problems that may arise with antibiotic management. ${ }^{32}$ It has been demonstrated that previous undesirable encounters can reduce the willingness of the patients to adhere to a course of antibiotics. ${ }^{33,34}$ The majority of the adolescents in this study population stated that they had had at least one negative experience with antibiotics. Further, a large number of respondents felt that antibiotics did not make them feel any better and observed that they had undesirable effects as a result of taking antibiotics. This has been noted in previous work ${ }^{13}$ and could lead to patients resisting the use of antibiotics in the future. With the need to properly adhere to antibiotic therapy, this will increase the risk of resistance in the long run. ${ }^{35}$ Interestingly, the present work also revealed that those exposed to negative experiences with antibiotics were more likely to have better knowledge of the correct usage of these medications.
Bad experiences may lead to the need to further understand the effects of medication and, hence, to higher knowledge levels. Therefore, understanding these experiences can lead to a meaningful construct for providing better medication education.

Another aspect to be considered when improving adherence is the engagement of patients in decision making. The shared decision-making process has proven valuable for younger adults as well adolescents, ${ }^{36-38}$ however, when considering adherence in this group of patients, shared decision making has been rarely addressed, especially in the context of short-term medication. ${ }^{37,38}$ In this instance, it was noted that the baseline preference for engagement in shared decision making among adolescents was mostly active and collaborative. Approximately one-third of the adolescents, however, were still reluctant to engage in decision making. To the best of our knowledge, Malaysian adolescents' preferences for engagement in decision making have not been reported before. Compared with other countries, the preference of the adolescents in this study to be collaboratively involved in decision making was notably lower. ${ }^{39}$

Interestingly, parents/caregivers that preferred a more collaborative decision-making approach for their child were also more willing to be collaboratively involved with their clinicians. However, an important finding was the high number of adolescents and their parents/caregivers who preferred an approach to decision making that was not collaborative. It is crucial to educate both parties about the need for a more collaborative approach. This will ensure that adolescents and their parents/caregivers are aware of the need for decisions to be made together with their clinicians to ensure the safety and effectiveness of treatment. Although better knowledge of antibiotic usage has been related to a more collaborative approach to decision making, ${ }^{40-42}$ no association was demonstrated in the current study population. The generally low knowledge of antibiotics could have reduced the likelihood of any associations to be observed in the study population.

This work provides a general understanding of the current level of knowledge about and attitude toward, as well as experience with, antibiotics among adolescents, and their preference for shared decision making. Despite its theoretical appeal, the concept of shared decision making is yet to be translated into practice, especially in the context of use of short-term medications, such as antibiotics, in local practice in Malaysia. However, it must be noted that as with all studies involving surveys, our results are dependent on the accuracy and honesty of the respondents answering the questionnaires. 
These respondents may have answered the survey in a manner that portrays them favorably. Generalization of the study results should be done cautiously due to these limitations.

Our most interesting finding was the general preference of adolescents and their parents/caregivers to be involved in the shared decision-making process. ${ }^{40-43}$ Further work could, therefore, be performed to observe whether education about correct antibiotic usage can promote involvement in the decision-making process. The responsibility to educate patients about the appropriate usage of antibiotics usually lies with health care personnel, such as pharmacists. To that end, education packages could be introduced to identify whether an improvement in antibiotic knowledge affects outcomes in regard to preference for shared decision making.

\section{Acknowledgments}

The current work was supported by the Fundamental Research Grant Scheme (FRGS/2/2013/SKK02/UKM/03/2) from the Ministry of Education, Malaysia.

\section{Disclosure}

The authors report no conflicts of interest in this work.

\section{References}

1. Elwyn G, Frosch D, Thomson R, et al. Shared decision making: a model for clinical practice. J Gen Intern Med. 2012;27(10):1361-1367.

2. Braddock $\mathrm{CH} 3 \mathrm{rd}$. The emerging importance and relevance of shared decision making to clinical practice. Med Decis Making. 2010;30 (5 Suppl):5S-7S.

3. Merenstein D, Diener-West M, Krist A, Pinneger M, Cooper LA. An assessment of the shared-decision model in parents of children with acute otitis media. Pediatrics. 2005;116(6):1267-1275.

4. Stivers T. Participating in decisions about treatment: overt parent pressure for antibiotic medication in pediatric encounters. Soc Sci Med. 2002;54(7):1111-1130.

5. Department of Health. The NHS Plan. London: HMSO; 2000.

6. Tucker CM, Petersen S, Herman KC, et al. Self-regulation predictors of medication adherence among ethnically different pediatric patients with renal transplants. J Pediatr Psychol. 2001;26(8):455-464.

7. Gardiner P, Dvorkin L. Promoting medication adherence in children. Am Fam Phys. 2006;74(5):793-798.

8. Winnick S, Lucas DO, Hartman AL, Toll D. How do you improve compliance? Pediatrics. 2005;115(6):e718-e724.

9. Lin GA, Fagerlin A. Shared decision making: state of the science. Circ Cardiovasc Qual Outcomes. 2014;7(2):328-334.

10. Bauchner H, Pelton SI, Klein JO. Parents, physicians, and antibiotic use. Pediatrics. 1999;103(2):395-401.

11. Yahya Umpong MI. National Surveillance of Antibiotic Resistance Report 2011. Putrajaya: Ministry of Health (Malaysia); 2011.

12. Okeke IN, Laxminarayan R, Bhutta ZA, et al. Antimicrobial resistance in developing countries. Part I: recent trends and current status. Lancet Infect Dis. 2005;5(8):481-493.

13. Leochico CF, Bartolo SS, Candelario SB, et al. Knowledge, attitude and experiences of grade six pupils of Saint Louis University - Lanoratory Elementary School on medication use. E-Int Sci Res J. 2010;2(3): 253-266.

14. Lim KK, Teh CC. A cross sectional study of public knowledge and attitude towards antibiotics in Putrajaya, Malaysia. South Med Rev. 2012; $5(2): 26-33$.
15. Krejcie RV, Morgan DW. Determining sample size for research activities. Educ Psychol Meas. 1970;30:607-610.

16. Singh JA, Sloan JA, Atherton PJ, et al. Preferred roles in treatment decision making among patients with cancer: a pooled analysis of studies using the Control Preferences Scale. Am J Manag Care. 2010;16(9): 688-696.

17. Henrikson NB, Davison BJ, Berry DL. Measuring decisional control preferences in men newly diagnosed with prostate cancer. $J$ Psychosoc Oncol. 2011;29(6):606-618.

18. Kryworuchko J, Stacey D, Bennett C, Graham ID. Appraisal of primary outcome measures used in trials of patient decision support. Patient Educ Couns. 2008;73(3):497-503.

19. Lee CR, Cho IH, Jeong BC, Lee SH. Strategies to minimize antibiotic resistance. Int J Environ Res Public Health. 2013;10(9):4274-4305.

20. Nicolini G, Sperotto F, Esposito S. Combating the rise of antibiotic resistance in children. Minerva Pediatr. 2014;66(1):31-39.

21. Coulter A, Collins A. Making Shared Decision Making a Reality: No Decision About Me, Without Me. London: The Kings Fund; 2011.

22. Beidler SM, Dickey SB. Children's competence to participate in healthcare decisions. JONAS Healthc Law Ethics Regul. 2001;3(3):80-87.

23. Moore L, Kirk S. A literature review of children's and young people's participation in decisions relating to health care. J Clin Nurs. 2010; 19(15-16):2215-2225.

24. Harrison C; Bioethics Committee, Canadian Pediatric Society. Treatment decisions regarding infants, children and adolescents. Paediatr Child Health. 2004;9(2):99-103.

25. United Nation Children's Fund. Implementation Handbook for the Convention on the Rights of the Child. 3rd ed. Geneva: UNICEF; 2007.

26. Department of Statistics (Malaysia). Population Distribution and Basic Demographic Characteristic Report 2010. Available from: http://www. statistics.gov.my/index.php?r=column/cthemeByCat\&cat=117\&bul_i $\mathrm{d}=$ MDMxdHZjWTk1SjFzTzNkRXYzcVZjdz09\&menu_id=L0pheU4 3NWJwRWVSZklWdzQ4TlhUUT09. Accessed May 1, 2015.

27. Lecky DM, McNulty CA. Current initiatives to improve prudent antibiotic use amongst school-aged children. J Antimicrob Chemother. 2013; 68(11):2428-2430.

28. Chan GC, Tang SF. Parental knowledge, attitudes and antibiotic use for acute upper respiratory tract infection in children attending a primary healthcare clinic in Malaysia. Singapore Med J. 2006;47(4): 266-270.

29. Ling Oh A, Hassali MA, Al-Haddad MS, Syed Sulaiman SA, Shafie AA, Awaisu A. Public knowledge and attitudes towards antibiotic usage: a cross-sectional study among the general public in the state of Penang, Malaysia. J Infect Dev Ctries. 2011;5(5):338-347.

30. Islahudin F, Ahmad Temizi M, Mohamed Shah N. Knowledge, attitudes and practices about antibiotic use among the general public in Malaysia. Southeast Asian J Trop Med Public Health. 2014;45(6):1474-1481.

31. Huang Y, Gu J, Zhang M, et al. Knowledge, attitude and practice of antibiotics: a questionnaire study among 2,500 Chinese students. $B M C$ Med Educ. 2013;13:163.

32. Buck ML. Self-medication by adolescents. Pediatr Pharm. 2007;13(5): $1-4$.

33. Stoelben S, Krappweis J, Rössler G, Kirch W. Adolescents' drug use and drug knowledge. Eur J Pediatr. 2000;159(8):608-614.

34. Bastiaens L. Knowledge, expectations, and attitudes of hospitalized children and adolescents in psychopharmacological treatment. $J$ Child Adolesc Psychopharmacol. 1992;2(3):157-171.

35. Yewale VN, Dharmapalan D. Promoting appropriate use of drugs in children. Int J Pediatr. 2012;2012:906570.

36. Kilkelly U, Savage E. Child Friendly Healthcare: A Report Commissioned by the Ombudsman for Children. Dublin: University College Cork; 2013. Available from: http://www.oco.ie/wp-content/ uploads/2014/03/ChildFriendlyHealthcareOCO.pdf. Accessed December 2, 2014.

37. Coyne I, Amory A, Kiernan G, Gibson F. Children's participation in shared decision-making: children, adolescents, parents and healthcare professionals' perspectives and experiences. Eur J Oncol Nurs. 2014; 18(3):273-280. 
38. Butz AM, Walker JM, Pulsifer M, Winkelstein M. Shared decision making in school age children with asthma. Pediatr Nurs. 2007;33(2): 111-116.

39. Miller VA. Parent-child collaborative decision making for the management of chronic illness: a qualitative analysis. Fam Syst Health. 2009; 27(3):249-266.

40. Kassam R, Volume-Smith C, Albon SP. Informed shared decision making: An exploratory study in pharmacy. Pharm Pract (Granada). 2008; 6(2):57-67.

41. Drotar D, Crawford P, Bonner M. Collaborative decision-making and promoting treatment adherence in pediatric chronic illness. Patient Intelligence. 2010;2:1-7.
42. The Magic Team. Pharmacy Professionals Use Shared Decision Making Approaches to Help Patients Better Understand their Medicines. Newcastle: The Health Foundation; 2014. Available from: http://personcentredcare.health.org.uk/sites/default/files/resources/ pharmacy_case_study.pdf. Accessed November 20, 2014.

43. Miller VA, Harris D. Measuring children's decision-making involvement regarding chronic illness management. J Pediatr Psychol. 2012; 37(3):292-306.

Patient Preference and Adherence

\section{Publish your work in this journal}

Patient Preference and Adherence is an international, peer-reviewed, open access journal that focuses on the growing importance of patient preference and adherence throughout the therapeutic continuum. Patient satisfaction, acceptability, quality of life, compliance, persistence and their role in developing new therapeutic modalities and compounds to optimize clinical outcomes for existing disease states are major areas of interest for the journal. This journal has been accepted for indexing on PubMed Central. The manuscript management system is completely online and includes a very quick and fair peer-review system, which is all easy to use. Visit http://www. dovepress.com/testimonials.php to read real quotes from published authors.

\footnotetext{
Submit your manuscript here: http://www.dovepress.com/patient-preference-and-adherence-journal
} 